\title{
Effective Double Electron Transport Layer Inducing Crystallization of Active Layer for Improving the Performance of Organic Solar Cells
}

\author{
Ping $\mathrm{Li}^{1, *,+}$, Lijia Chen ${ }^{2,+}$, Xiaoyan $\mathrm{Hu}^{1}{ }^{1}$, Lirong $\mathrm{He}^{1}$, Zezhuan Jiang ${ }^{1}$, Minghao Luo ${ }^{1}$, Haishen Huang ${ }^{1}(\mathbb{D}$, \\ Wei Yuan ${ }^{3}$ and Yinghu $\mathrm{He}^{1}$ \\ 1 School of Physics and Electronic Science, Zunyi Normal University, Zunyi 563006, China; \\ XY1005499@126.com (X.H.); helirong9527@126.com (L.H.); zezhuan」@126.com (Z.J.); \\ lmh18311641321@126.com (M.L.); haishenh@yeah.net (H.H.); hyhv@sina.com (Y.H.) \\ 2 College of Physics and Electronic Engineering, Chongqing Normal University, Chongqing 401331, China; \\ ljchen01@cqnu.edu.cn \\ 3 Department of Rail Transportation Engineering, GuiZhou Communication Polythechnic, \\ Guiyang 551400, China; windyuanwei@126.com \\ * Correspondence: LIP19870212@126.com \\ + These authors contributed equally to this work.
}

check for updates

Citation: Li, P.; Chen, L.; Hu, X.; He, L.; Jiang, Z.; Luo, M.; Huang, H.; Yuan, W.; He, Y. Effective Double Electron Transport Layer Inducing Crystallization of Active Layer for Improving the Performance of Organic Solar Cells. Nanomaterials 2022, 12, 15. https://doi.org/ 10.3390/nano12010015

Academic Editor: Antonio Di Bartolomeo

Received: 16 November 2021 Accepted: 14 December 2021 Published: 22 December 2021

Publisher's Note: MDPI stays neutral with regard to jurisdictional claims in published maps and institutional affiliations.

Copyright: () 2021 by the authors. Licensee MDPI, Basel, Switzerland. This article is an open access article distributed under the terms and conditions of the Creative Commons Attribution (CC BY) license (https:// creativecommons.org/licenses/by/ $4.0 /)$.

\begin{abstract}
Interface modification plays an important role in enhancing the photoelectric conversion efficiency and stability of organic solar cells. In this work, alkali metal lithium chloride (LiCl) was introduced between indium tin oxide and polyethyleneimine ethoxylate (PEIE) to prepare a doublelayer electron transport layer. Results show that the introduction of $\mathrm{LiCl}$ has dual functions. The first function is that $\mathrm{LiCl}$ can enhance conductivity, thereby facilitating charge collection. The second function is that the double-layer electron transport layer based on $\mathrm{LiCl}$ can induce the crystallization of active layer, thereby enhancing charge transport. Devices with $\mathrm{LiCl} / \mathrm{PEIE}$ double layer achieve a high power conversion efficiency (PCE) of 3.84\%, which is $21.5 \%$ higher than that of pristine devices (the PCE of pristine devices with pure PEIE interface layer is $3.16 \%$ ).
\end{abstract}

Keywords: organic solar cell; electron transport layer; LiCl; PEIE

\section{Introduction}

Organic solar cells (OSCs) have attracted the attention of many researchers due to their advantages, such as flexible large-scale production and low fabrication costs. In recent years, the reported power conversion efficiency (PCE) of single-junction OSCs has exceeded $18 \%[1,2]$. However, OSC S have low conversion efficiency and poor stability compared with silicon-based solar cells, which is one of the main reasons that the commercial development of OSCs is limited [3]. Many methods, such as designing new device structure, synthesizing new materials, improving manufacturing processes, and interface modification, were used to improve the performance of OSCs. Interface modification plays an important role in the long-term stability and the improvement of the PCE of the device [4-7]. Lin et al. used $\mathrm{WS}_{2}$ rather than PEDOT:PSS to modify the interface of a device, and the PCE of the modified device is as high as $17.3 \%$ [8]. An appropriate interface modification material is extremely important for the preparation of efficient and stable OSCs. Currently, metal oxides, such as titanium oxide $\left(\mathrm{TiO}_{\mathrm{X}}\right)$, zinc oxide $(\mathrm{ZnO})$, and stannic oxide $\left(\mathrm{SnO}_{2}\right)$, are commonly used as charge transport materials [9-13]. However, these materials can cause some defects during the preparation of interface layer due to their inherent properties. For example, metal oxides cannot form a uniform thin film with a smooth surface on indium tin oxide (ITO) due to their insolubility in solution, thereby increasing charge recombination loss and leakage current and leading to a poor efficiency of the device. To address these issues, researchers proposed to use high solubility materials rather than low solubility 
interface materials. Polyethyleneimine ethoxylated (PEIE) is a polymer material that can be well-dispersed in the solution and is widely used in OSCs and organic light-emitting diode devices [14]. PEIE can fabricate a uniform and smooth film on ITO. However, PEIE is an insulating material, thereby hindering charge transportation. A double-layer charge transport layer prepared using two different types of materials is proposed as an electron transport layer (ETL) in OSC. Yu et al. used ZnO:PEIE composites with different PEIE concentrations as the double-layer ETL of OSC. Compared with pure ZnO as the ETL, the PCE of a device with double-layer ETL is effectively increased from 3.01\% to 3.52\% [15]. Kim et al. reported that a PCE of $8.21 \%$ is obtained for a device with graphene and polymer PEIE as a double ETL based on PTB7:PC ${ }_{71}$ BM active materials [16].

Alkali metal lithium chloride $(\mathrm{LiCl})$ has good electrical conductivity and is widely used in perovskite solar cells and OSCs [17-19]. Ling et al. combined $\mathrm{LiCl}$ with $\mathrm{ZnO}$ as an ETL, and a PCE of 3.62\% for polymer solar cells based on the poly (3-hexylthiophene) and [6,6]-phenyl-C61-butyric acid methyl ester (P3HT:PC61BM) system was obtained [17]. Sheng et al. added $\mathrm{LiCl}$ in the perovskite solution, which effectively increases the conductivity of the device, and the efficiency of the device is significantly improved [19]. They indicated that $\mathrm{Li}$ ions can enhance the conductivity in perovskite solar cell and promote the crystallization of perovskite film $[20,21]$. By taking advantage of the conductivity of Li ions, the combination $\mathrm{LiCl}$ and PEIE with insulating properties is expected to improve the conductivity of the interface modification layer. Relevant studies have not been reported. In this work, $\mathrm{LiCl}$ and PEIE were combined as a double-layer ETL to fabricate OSCs on the basis of P3HT:PC61BM. A high PCE of 3.84\% was achieved for the device with LiCl/PEIE double layer. The effect of the introduction of $\mathrm{LiCl}$ on the performance of OSCs and the mechanism process was studied.

\section{Materials and Methods}

\subsection{Materials}

The ITO glass substrates were purchased from Shenzhen Huanan Xiangcheng Technology Co., Ltd. (Shenzhen, China) (transmittance $\geq 89 \%$ ), and anhydrous 2-methoxyethanol $(99.8 \%)$ and polyethyleneimine (PEIE, 37\%) were purchased from Sigma Aldrich (St. Louis, MO, USA). PCBM, P3HT, thieno[3,4-b] thiophene/benzodithiophene (PTB7), [6,6]-phenyl $\mathrm{C}_{71}$-butyric acid methyl ester $\left(\mathrm{PC}_{71} \mathrm{BM}\right)$ and $\mathrm{LiCl}(99.5 \%)$ were purchased from J\&K Chemicals (Beijing, China). Metallic silver (Ag, 99\%), molybdenum trioxide $\left(\mathrm{MoO}_{3}, 99 \%\right)$, and bath copper spirit (BCP, 99\%) were provided by Xi'an Polymer Light Technology Corp (Xi'an, China).

\subsection{Device Preparation}

The ITO glass substrates were continuously and ultrasonically cleaned with cleaning agent, absolute ethanol, acetone, and isopropanol for $20 \mathrm{~min}$. The devices were dried with nitrogen and underwent plasma treatment. The OSCs with the structure of ITO/PEIE or X-LiCl-PEIE/P3HT:PCBM/ $\mathrm{MoO}_{3} / \mathrm{Ag}$ were fabricated, where $\mathrm{X}$ represents $\mathrm{LiCl}$ aqueous solutions with concentrations of $0.5,1,2,5$, and $10 \mathrm{mg} / \mathrm{mL}$, which were marked as pure PEIE, 0.5-LiCl-PEIE, 1-LiCl-PEIE, 2-LiCl-PEIE, 5-LiCl-PEIE, and 10-LiCl-PEIE, respectively. For the fabrication of the devices, the $\mathrm{LiCl}$ aqueous solution with various concentrations was spin-coated on the surface of the treated ITO at $2000 \mathrm{rpm}$ for $40 \mathrm{~s}$ and then thermal annealed in air at $120^{\circ} \mathrm{C}$ for $20 \mathrm{~min}$. After cooling to room temperature, a certain concentration of PEIE solution was spin-coated on the surface of the $\mathrm{LiCl}$ film at $4000 \mathrm{rpm}$ for $60 \mathrm{~s}$ and then thermal annealed in air at $120^{\circ} \mathrm{C}$ for $15 \mathrm{~min}$ to obtain the $\mathrm{LiCl} / \mathrm{PEIE}$ double-layer ETL. After cooling, the ITO glass substrates with ETL were transferred in a glovebox for fabricating the active layer. The P3HT:PCBM solution (35 mg/mL of concentration, P3HT:PCBM = 18:17) and PTB7:PC ${ }_{71} \mathrm{BM}$ solution $\left(25 \mathrm{mg} / \mathrm{mL}\right.$, PTB7:PC $\left.{ }_{71} \mathrm{BM}=1: 1.5\right)$ were spin-coated on the prepared ETL at a speed of $870 \mathrm{r} / \mathrm{min}$ for $40 \mathrm{~s}$. The samples with active layer were then transferred to the growth chamber of high-vacuum thermal evaporation. $\mathrm{A} \mathrm{MoO}_{3}$ thin film with a thickness of $6 \mathrm{~nm}$ and a Ag film with a thickness of $60 \mathrm{~nm}$ were grown at 
0.01 and $0.05 \mathrm{~nm} / \mathrm{s}$ as a hole transport layer and an electrode, respectively. During the growth process of $\mathrm{MoO}_{3}$ and $\mathrm{Ag}$ electrodes, the vacuum degree of the growth chamber was controlled below $1 \times 10^{-4} \mathrm{~Pa}$. Shadow mask was used during thermal evaporation to define the active area of $0.09 \mathrm{~cm}^{2}$ for the devices. The pristine device was a pure PEIE as an ETL and was marked as pure PEIE device.

\subsection{Characterization of Films and Inverted OSCS}

The current-voltage (I-V) characteristics of the devices were measured by using $100 \mathrm{~mW} / \mathrm{cm}^{2}$ simulated sunlight AM 1.5G and a Keithley 2400 SourceMeter purchased from Zuoli (Beijing, China). Electrochemical impedance spectroscopy (EIS) was measured using a CS Series electrochemical workstation purchased from Wuhan Kesite Company (Wuhan, China). The conductivity of devices was evaluated using Keithley 2400. X-ray diffraction (XRD) patterns were obtained using an XRD with $\mathrm{Cu} K \alpha 1$ radiation $(\lambda 1 / 41.5406)$, with generation power of $40 \mathrm{kV}$ tube voltage and $40 \mathrm{~mA}$ tube current operated in the locked couple mode. The morphology of the active layer was characterized through atomic force microscopy (AFM). The absorption spectrums of the active layers were measured with an ultraviolet-visible (UV-vis) photometer.

\section{Results and Discussion}

Pure PEIE and $X-\mathrm{LiCl} / \mathrm{PEIE}$ (where $X$ is $0.5,1,2,5$, and $10 \mathrm{mg} / \mathrm{mL}$ ) were used as an ETL. OSC devices with the structure of ITO/ETL/P3HT:PCBM/MoO $/$ Ag were fabricated and marked as pure PEIE, 0.5-LiCl-PEIE, 1-LiCl-PEIE, 2-LiCl-PEIE, 5-LiCl-PEIE, and 10-LiCl-PEIE, respectively. All devices were characterized using a solar simulator with 1 sun AM $1.5 \mathrm{G}$ illumination $\left(100 \mathrm{~mW} \cdot \mathrm{cm}^{-2}\right)$. The I-V curves of the OSCs based on different ETLs are depicted in Figure 1a. The performance parameters of the OSCs, including short-circuit current $\left(J_{s c}\right)$, open-circuit voltage $\left(V_{o c}\right)$, fill factor $(F F)$, and PCE are summarized in Table 1. The devices of the best PCEs were used for the following discussion. With only PEIE as ETLs (pure PEIE), the device yields a PCE of $3.19 \%, J_{S C}$ of $8.32 \mathrm{~mA} \cdot \mathrm{cm}^{-2}$, $V_{o c}$ of $0.58 \mathrm{~V}$, and FF of $65.5 \%$. The performance of the OSCs is remarkably enhanced by inserting $\mathrm{LiCl}$ between ITO and PEIE as ETLs. $J_{S C}$ increases from $8.32 \mathrm{~mA} \cdot \mathrm{cm}^{-2}$ to $10.36 \mathrm{~mA} \cdot \mathrm{cm}^{-2}$ when the $\mathrm{LiCl}$ concentration increases from $0 \mathrm{mg} / \mathrm{mL}$ to $1 \mathrm{mg} / \mathrm{mL}$ and then constantly reduces to $8.16 \mathrm{~mA} \cdot \mathrm{cm}^{-2}$ when the $\mathrm{LiCl}$ concentration increases to $10 \mathrm{mg} / \mathrm{mL}$. Highest PCE of $3.84 \%, J_{s c}$ of $10.36 \mathrm{~mA} \cdot \mathrm{cm}^{-2}, V_{o c}$ of $0.58 \mathrm{~V}$, and FF of $62.8 \%$ are obtained by the device with 1-LiCl-PEIE as ETL. Compared with the pristine device, the PCE of the device with 1-LiCl-PEIE ETL improves by $21.5 \%$. The enhancement in PCE is mainly contributed by the increasing $J_{s c}$, which is consistent with the smallest $R_{S}$ of $7.5 \Omega \cdot \mathrm{cm}^{2}$ and largest $R_{s h}$ of $1982 \Omega \cdot \mathrm{cm}^{2}$. The same trend was observed by the PTB7:PC 71 BM-based devices and shown in supporting information (Figure 1b). With only PEIE as ETLs, the PTB7:PC ${ }_{71}$ BM-based device yields a PCE of $6.11 \%, J_{S C}$ of $17.27 \mathrm{~mA} \mathrm{~cm}^{-2}, V_{o c}$ of $0.69 \mathrm{~V}$, and FF of $51.2 \%$. The highest PCE of $7.33 \%, J_{s c}$ of $19.07 \mathrm{~mA} \mathrm{~cm}^{-2}, V_{o c}$ of $0.69 \mathrm{~V}$, and FF of $55.4 \%$ are obtained by the PTB7:PC 71 BM-based device with 1-LiCl-PEIE as an ETL. Compared with the pristine device, the PCE of the device with 1-LiCl-PEIE ETL improves by $19.6 \%$. The result indicates that the introduction of $\mathrm{LiCl}$ may reduce the interface contact resistance and charge recombination loss, thereby enhancing the charge transport ability and improving the $J_{s c}$ of device with $\mathrm{LiCl} / \mathrm{PEIE}$ as an ETL. 

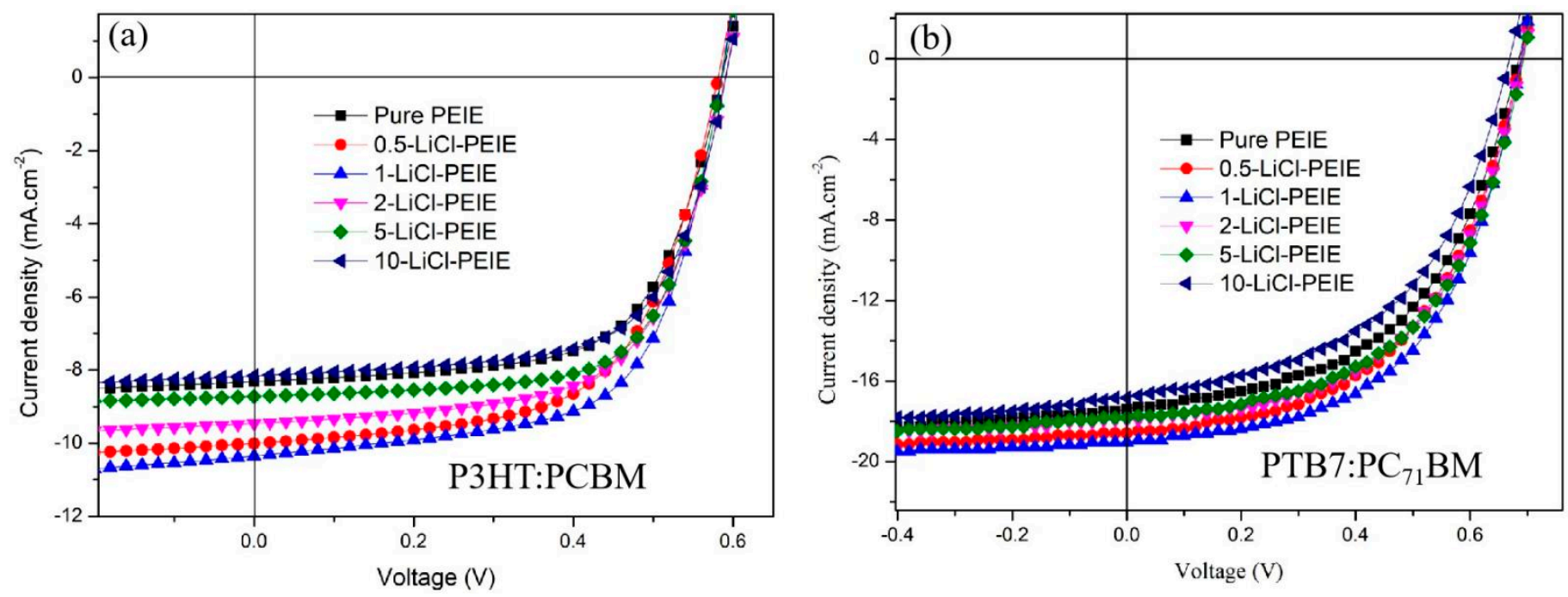

Figure 1. $I-V$ curves of OSCs based on different ETLs, (a) P3HT:PCBM-based devices and (b) PTB7:PC 71 BM-based devices.

Table 1. Performance parameters of P3HT:PCBM-based OSCs with different ETLs. The presented value is the best one observed in this study.

\begin{tabular}{|c|c|c|c|c|c|c|c|}
\hline \multirow{2}{*}{ Device } & \multirow{2}{*}{$V_{o}(\mathrm{~V})$} & \multirow{2}{*}{$J_{s c}\left(\mathrm{~mA} \cdot \mathrm{cm}^{-2}\right)$} & \multirow{2}{*}{$F F(\%)$} & \multirow{2}{*}{$R_{s}\left(\Omega \cdot \mathrm{cm}^{2}\right)$} & \multirow{2}{*}{$R_{s h}\left(\Omega \cdot \mathrm{cm}^{2}\right)$} & \multicolumn{2}{|c|}{ PCE (\%) } \\
\hline & & & & & & Highest & Average $^{a}$ \\
\hline Pure PEIE & 0.58 & 8.32 & 65.5 & 11.3 & 1281 & 3.16 & 3.04 \\
\hline 0.5-LiC-PEIE & 0.58 & 10.01 & 60.1 & 9.6 & 1832 & 3.54 & 3.43 \\
\hline 1-LiCl-PEIE & 0.58 & 10.36 & 62.8 & 7.5 & 1982 & 3.84 & 3.61 \\
\hline 2-LiCl-PEIE & 0.58 & 9.44 & 64.4 & 9.9 & 1652 & 3.53 & 3.21 \\
\hline 5-LiCl-PEIE & 0.58 & 8.72 & 68.2 & 11.7 & 1127 & 3.45 & 3.19 \\
\hline 10-LiCl-PEIE & 0.59 & 8.16 & 66.0 & 15.1 & 987 & 3.12 & 2.98 \\
\hline
\end{tabular}

${ }^{a}$ Average over 10 devices.

The I-V curves of the device with the structure of ITO/PEIE (or X-LiCl/PEIE)/P3HT: $\mathrm{PCBM} / \mathrm{BCP} / \mathrm{Ag}$ are recorded to understand the enhancement of $J_{s c}$ from the contribution of the $\mathrm{LiCl} / \mathrm{PEIE}$ double layer, as shown in Figure 2, where the values of $X$ are $0.5,1,2,5$, and $10 \mathrm{mg} / \mathrm{mL}$. The slope of the I-V curves for the device corresponds to the conductivity of the ETL films. The slope of the device with $\mathrm{LiCl}$ increases with the increase in $\mathrm{LiCl}$ concentration, and the largest slope is achieved at $1 \mathrm{mg} / \mathrm{mL}$ of $\mathrm{LiCl}$. With the increase in $\mathrm{LiCl}$ concentration, the slope gradually decreases. The smallest slope is achieved at $10 \mathrm{mg} / \mathrm{mL}$ of $\mathrm{LiCl}$. This result is consistent with the $\mathrm{I}-\mathrm{V}$ measurement in Figure 1 . This finding indicates that the $\mathrm{LiCl} / \mathrm{PEIE}$ double layer with $1 \mathrm{mg} / \mathrm{mL} \mathrm{LiCl}$ has the optimal conductivity ability, and high concentration of $\mathrm{LiCl}$ leads to the reduction in conductivity. The EIS of the OSCs based on P3HT:PCBM is measured in the light state to confirm whether the conductivity of $\mathrm{LiCl} / \mathrm{PEIE}$ as an ETL can be increased and the resistance at the interface between ITO and the active layer can be reduced, as shown in Figure $2 \mathrm{~b}$. These experimental results can be well-fitted by using the equivalent circuit shown in the inset of Figure $2 \mathrm{~b}$, as shown in Table 2, where $R_{0}, R_{1}$, and $R_{2}$ are the series resistance, transfer resistance in ETL, and charge recombination resistance at the interface between ETL and the active layer, respectively [22,23]. As shown in Table 2, the smallest $R_{0}$ of this device is achieved. This result indicates that the enhancement in conductivity is attributed to the formation of ohmic contact between the $\mathrm{LiCl} / \mathrm{PEIE}$ and the active layer. The smallest values of $R_{1}$ and $R_{2}$ are found for the best performing device with 1-LiCl/PEIE ETL, which are 50.78 and $170.17 \Omega$, respectively. These results indicate that the insertion of a certain amount of $\mathrm{LiCl}$ between PEIE and ITO can enhance the charge transfer rate and reduce the recombination at the interface between the ETL and ITO. However, LiCl/PEIE ETL 
with high $\mathrm{LiCl}$ concentration increases the interface resistance, thereby improving charge recombination and leading to photocurrent reduction. The largest charge recombination of the device with 10-LiCl/PEIE ETL found by EIS measurements is consistent with the smallest $J_{S C}$ of this device in Figure 1 a.
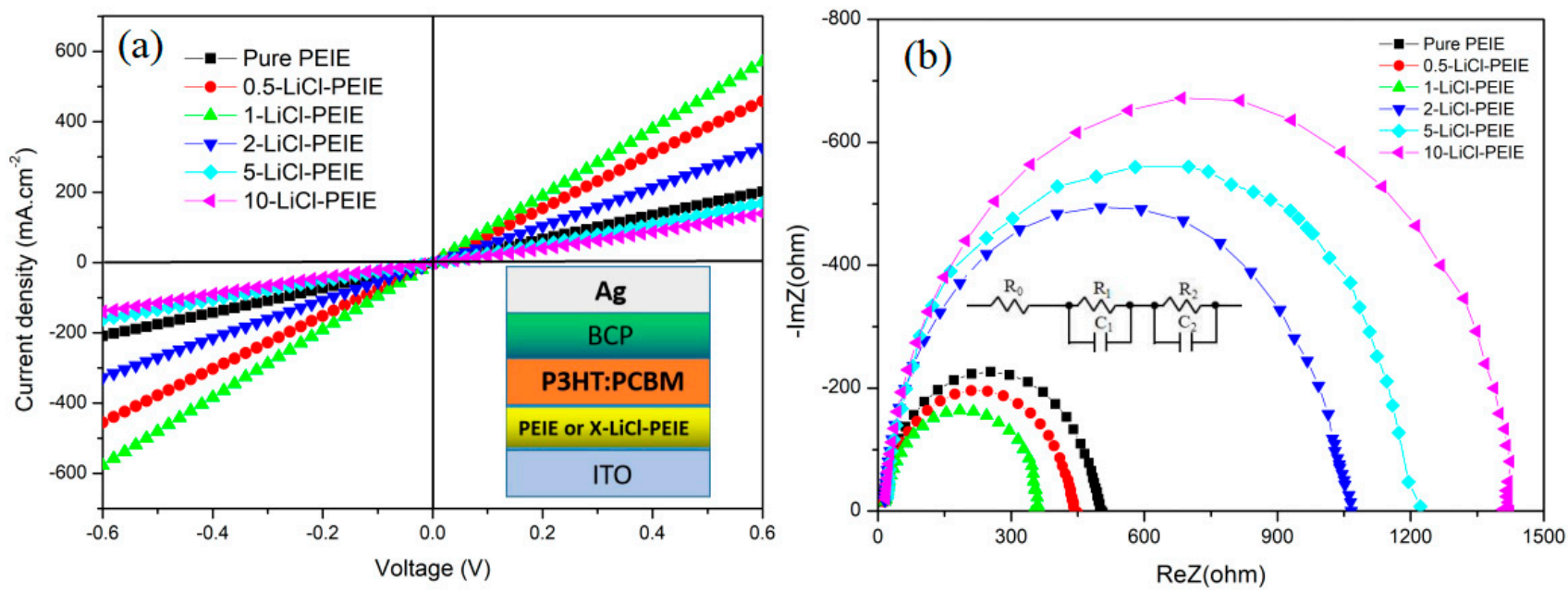

Figure 2. (a) I-V curves of the device with the structure of ITO/PEIE (X-LiCl/PEIE)/P3HT: $\mathrm{PCBM} / \mathrm{BCP} / \mathrm{Ag}$. (b) EIS of P3HT:PCBM-based OSCs with different LiCl/PEIE interfacial layers.

Table 2. EIS of OSCs based on different ETLs.

\begin{tabular}{cccc}
\hline Device & $\boldsymbol{R}_{\mathbf{0}}(\boldsymbol{\Omega})$ & $\boldsymbol{R}_{\mathbf{1}}(\boldsymbol{\Omega})$ & $\boldsymbol{R}_{\mathbf{2}}(\boldsymbol{\Omega})$ \\
\hline Pure PEIE & 85.23 & 79.15 & 332.12 \\
0.5-LiC-PEIE & 73.14 & 68.51 & 285.54 \\
1-LiCl-PEIE & 62.42 & 50.78 & 170.17 \\
2-LiCl-PEIE & 130.73 & 127.61 & 433.16 \\
5-LiCl-PEIE & 178.81 & 153.52 & 489.22 \\
10-LiCl-PEIE & 245.95 & 331.19 & 888.25 \\
\hline
\end{tabular}

Considering the contribution of absorption to the photocurrent, two half-cells with the structure of ITO/PEIE/P3HT:PCBM and ITO/X-LiCl/PEIE/P3HT:PCBM were fabricated to measure the light absorption of the P3HT:PCBM active layer, where the values of $X$ are $0.5,1,2,5$, and $10 \mathrm{mg} / \mathrm{mL}$. As shown in Figure 3a, the absorption of P3HT:PCBM film with $\mathrm{LiCl} / \mathrm{PEIE}$ is slightly higher than that of the active layer film with pure PEIE. When the $\mathrm{LiCl}$ aqueous solution is $1 \mathrm{mg} / \mathrm{mL}$, the light absorption is the highest, which is consistent with the largest $J_{s c}$ of this device in Figure 1a. This enhancement in light absorption may be ascribed to the P3HT:PCBM crystallization induced by introducing $\mathrm{LiCl}$. An XRD analysis of the P3HT:PCBM film with PEIE and 1-LiCl was conducted to confirm whether the $\mathrm{LiCl}$ induces P3HT:PCBM crystallization, as depicted in Figure 3b. A peak around $5.4^{\circ}$ can be observed in all films, which is assigned to the crystallographic plane (100) of P3HT crystals [24]. The diffraction intensity of P3HT:PCBM films with LiCl/PEIE is higher compared with a film with pure PEIE, indicating that more crystalline P3HT is formed in films with $\mathrm{LiCl} / \mathrm{PEIE}$ (Figure 3b). These results indicate that the P3HT:PCBM crystallization can be induced by introducing $\mathrm{LiCl}$.

To further understand the charge recombination characteristics, the light intensity dependent $J_{S c}$ and $V_{o c}$ characteristics for the device with pure or 1-LiCl-PEIE were measured and shown in Figure 4. An $\alpha$ value of 0.96 was obtained for the device with 1-LiCl-PEIE. The relatively small $\alpha$ value was determined to be 0.92 for the device with pure PEIE, suggesting the LiCl-based double layer reduces the bimolecular recombination (Figure 4a). The reduction in bimolecular recombination can be attributing to the decrease in defect for P3HT:PCBM film. The defect can create the trap state. The trap state will result in the charge recombination. The slope of $1.39 \mathrm{kT} / \mathrm{q}$ for the device with pure PEIE is bigger than 
that of $1.24 \mathrm{kT} / \mathrm{q}$ for the device with 1-LiCl-PEIE (Figure 4b) [25]. The result hints that the LiCl-based double layer can effectively suppress the trap-assisted recombination [26], suggesting further promoting the extraction of charge. The enhancement in the extraction of charge can be confirmed by the higher rectification ratio for the device with 1-LiClPEIE compared with the device with PEIE (Figure $4 \mathrm{c})$. The photocurrent $\left(J_{p h}\right)$ versus the effective voltage $\left(V_{\text {eff }}\right)$ was measured to understand charge extraction [25]. $J_{p h}$ is given by $J_{p h}=J_{L}-J_{D}$, where $J_{L}$ is the current density under light illumination and $J_{D}$ is the dark current density. $V_{\text {eff }}$ is given by $V_{\text {eff }}=V_{0}-V$, where $V_{0}$ is the compensation voltage where $J_{p h}=0 \mathrm{~mA} \mathrm{~cm}{ }^{2}$ and $V$ is the applied bias voltage. A dramatic saturation regime was observed for the device with 1-LiCl-PEIE (Figure 4d), which suggests a negligible trapped charge and effective charge extraction/collection. The device with pure PEIE showed no clear saturation regime in $J_{p h}$ with increasing $V_{\text {eff, }}$, indicating significant electron-hole recombination. In addition, the photocurrent density of the device with 1-LiCl-PEIE was higher than that of the device with pure PEIE, suggesting higher charge extraction in the $\mathrm{LiCl}$-based device. These results are consistent with the photovoltage characteristics, EIS, and conductivity analysis.

The surface morphology of the P3HT:PCBM film with various ETLs was investigated. The AFM surface images of the P3HT:PCBM film with pure and LiCl/PEIE ETL are shown in Figure 5. The surface roughness of P3HT:PCBM film with PEIE is $5.8 \mathrm{~nm}$, which is consistent with the previously reported result [27], as shown in Figure 5a. The surface roughness of the P3HT:PCBM film with 1-LiCl/PEIE and 5-LiCl/PEIE ETL is measured as 7.96 and $6.59 \mathrm{~nm}$, respectively, as depicted in Figure 5b,c. The increase in roughness is related to the improvement in crystallinity of the two phases [28,29]. This condition suggests a better charge separation and charge carrier mobility in the two phases for the samples with the $\mathrm{LiCl} / \mathrm{PEIE}$ interface layer. Some defects are observed on the surface of the P3HT:PCBM film with PEIE ETL. By contrast, a uniform surface is observed on the surface of the P3HT:PCBM film with LiCl/PEIE ETL. This finding indicates that the introduction of $\mathrm{LiCl}$ can reduce the trap state of the P3HT:PCBM film. The increase in crystallization and the decrease in defect for the P3HT:PCBM film are beneficial to promote the charge transport in an active layer, resulting in the enhancement of $J_{s c}$ of the device and improving the performance of OSCs.
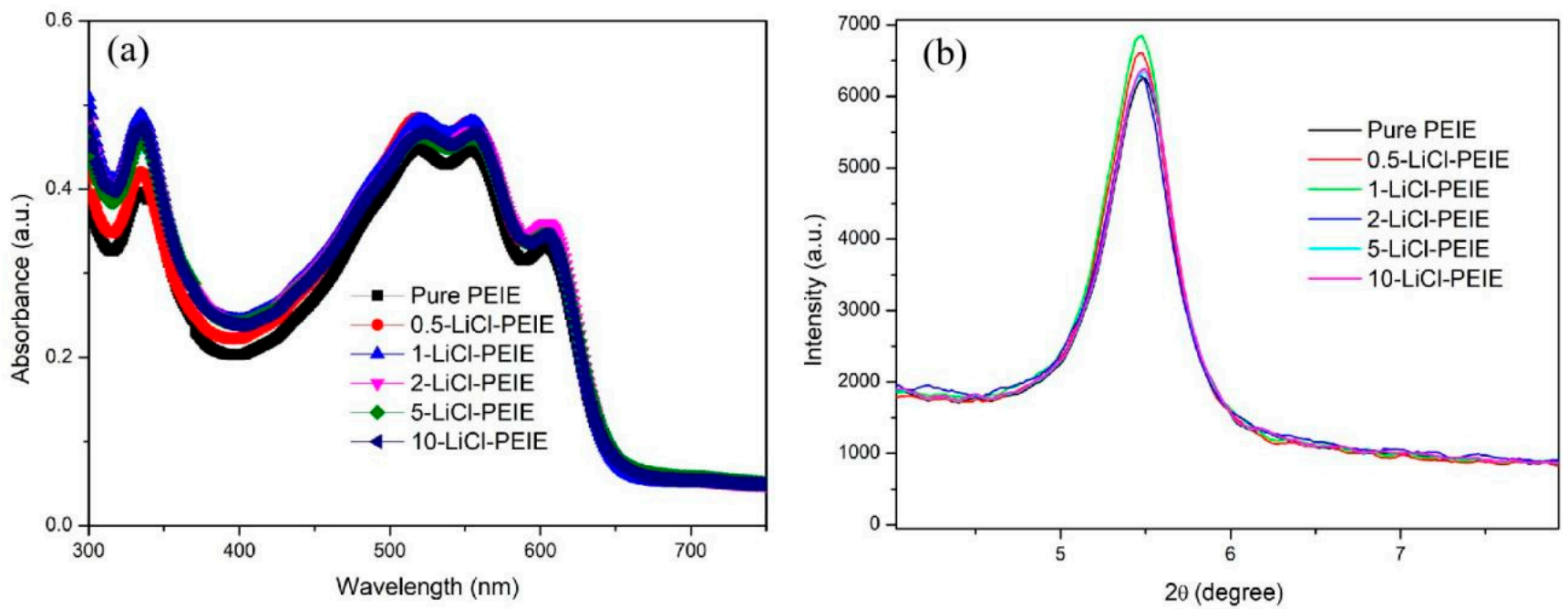

Figure 3. (a) Absorbance spectrum and (b) XRD of P3HT:PCBM film with various ETLs. 

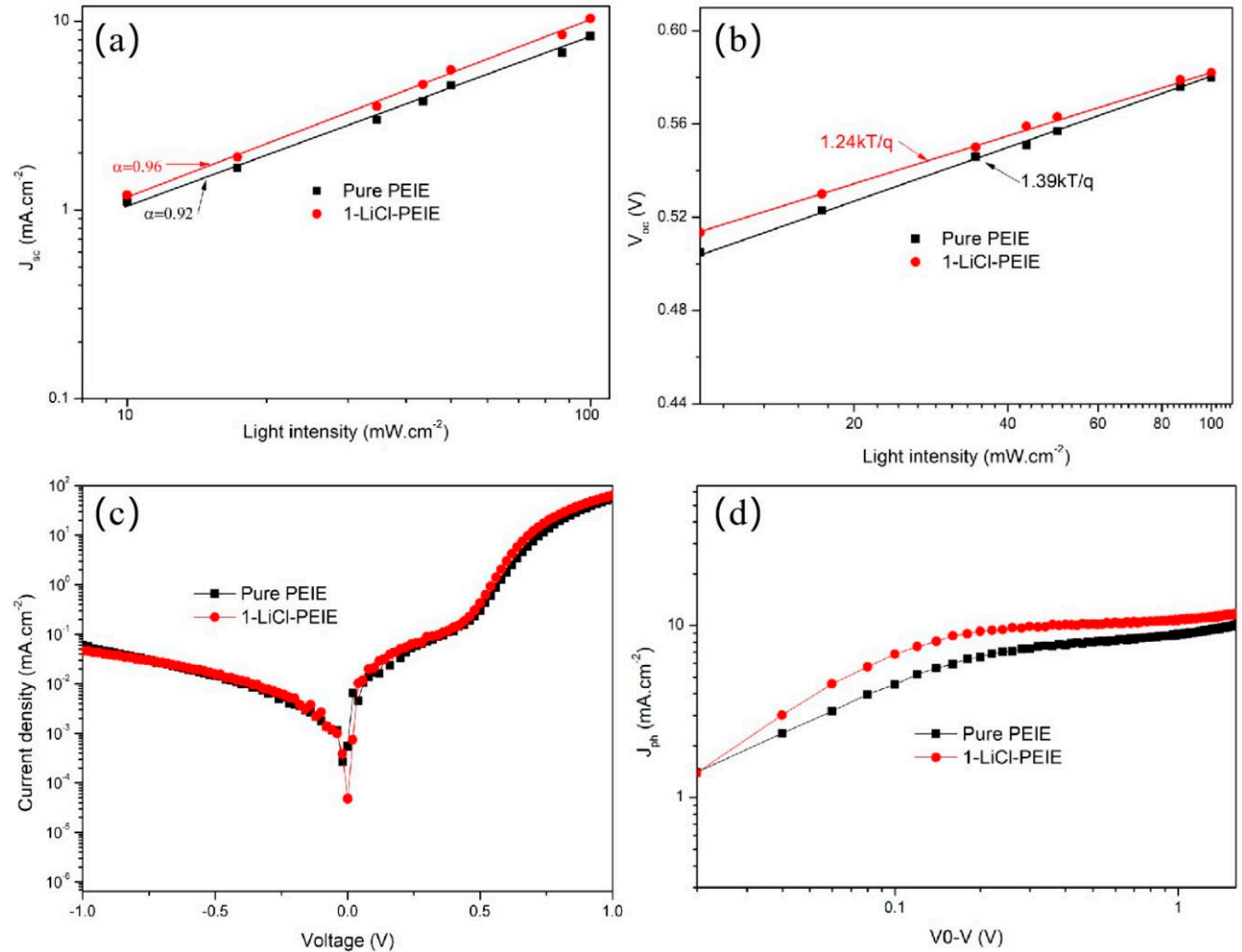

Figure 4. (a) Light intensity dependence of short circuit current $\left(J_{s c}\right)$, (b) light intensity dependence of open-circuit voltage $\left(V_{o c}\right)$, (c) I-V curves in the dark, $(\mathbf{d})$ photocurrent $\left(J_{p h}\right)$ measurement for devices with pure PEIE and 1-LiCl-PEIE ETLs.
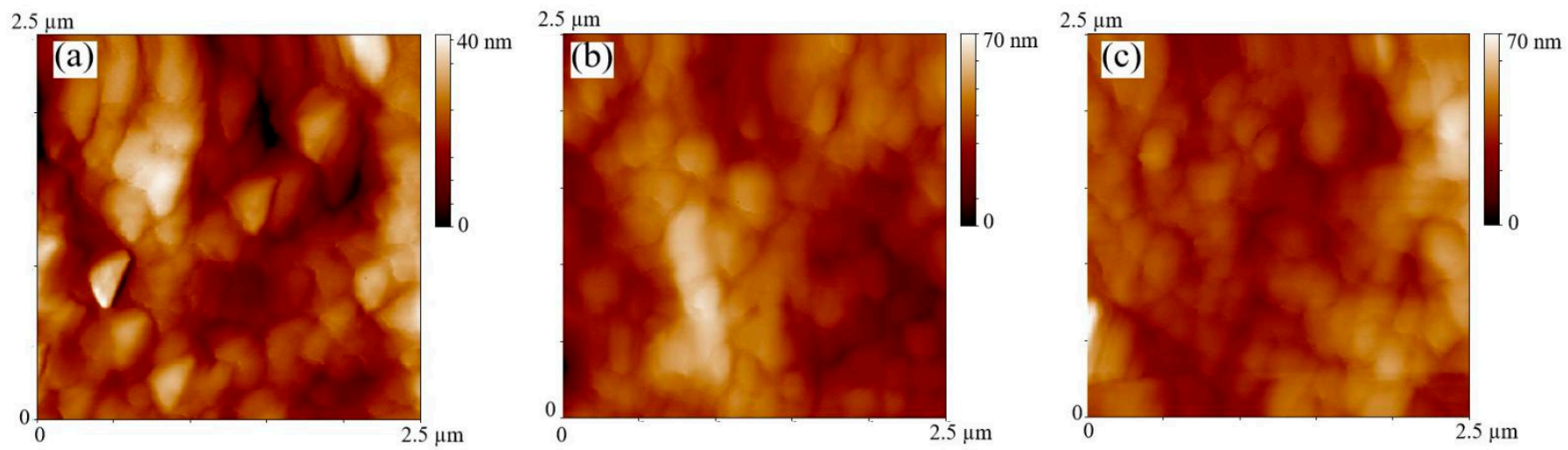

Figure 5. Surface morphology of the P3HT:PCBM film with PEIE (a) and 1-LiCl/PEIE (b) or 5 - $\mathrm{LiCl} /$ PEIE ETL (c). The scan size is $2.5 \mu \mathrm{m} \times 2.5 \mu \mathrm{m}$.

In addition, long-term stability of the unencapsulated devices with different ETLs in the $\mathrm{N}_{2}$ atmosphere with one sun illumination at $25^{\circ} \mathrm{C}$ were evaluated and shown in Figure 6. After 120 days, PCE of the LiCl-based device is higher than that of the device with pure PEIE except for the 10-LiCl-PEIE device, indicating the device's stability can be improved by a double-layer ETL. 


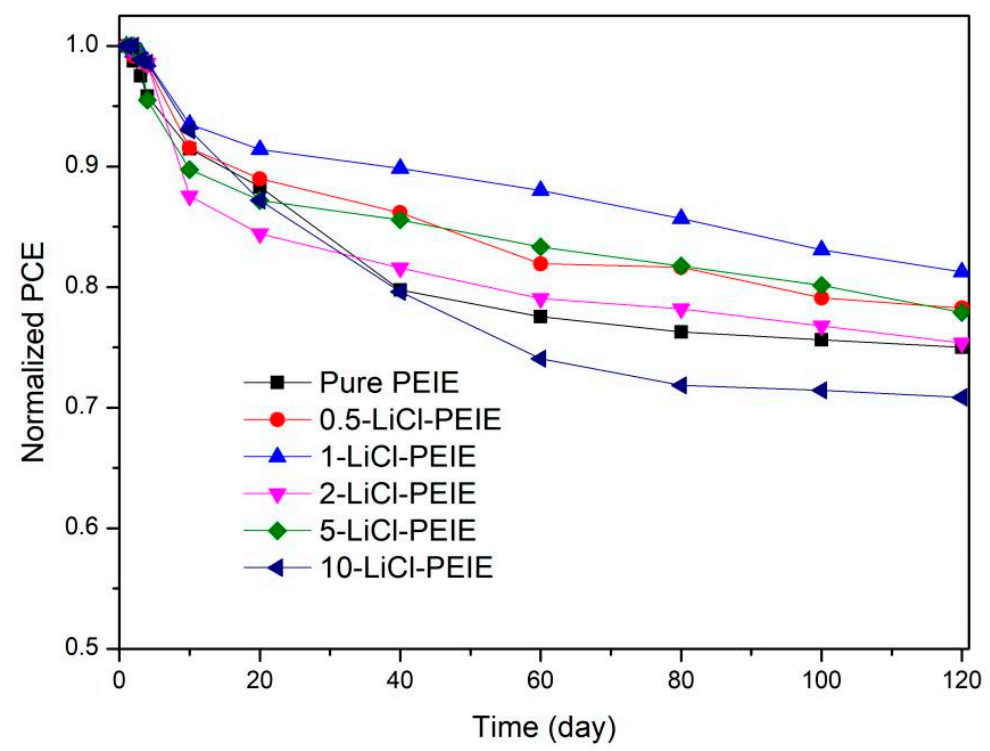

Figure 6. Long-term stability of the unencapsulated devices with different ETLs in N2 atmosphere with one sun illumination at $25^{\circ} \mathrm{C}$.

\section{Conclusions}

In this study, an OSC with an efficiency of 3.84\% was prepared using LiCl/PEIE as an ETL. An EIS analysis and conductivity measurement of the device indicate that $\mathrm{LiCl} / \mathrm{PEIE}$ as the double-layer ETL and is conducive to improving the conductivity of electrons due to the reduction in the contact resistance of interface between the ITO and active layer compared with the single-layer PEIE ETL. XRD, UV-vis, and AFM characterization indicate that the introduction of $\mathrm{LiCl}$ is beneficial to enhancing the crystallization of the active layer film, reducing the trap state, and improving the transport of free carriers, resulting in the enhancement of $J_{s c}$, and improving the performance of the device. This study proposed an effective method to fabricate the high efficiency solar cells.

Author Contributions: P.L. conceived the idea and supervised the project; X.H. fabricated the texture ETL, carried out the I-V measurements; L.H. carried out EIS and conductivity measurements; Z.J. carried out the AFM measurement; M.L. carried out the XRD measurement; W.Y. and Y.H. fabricated the devices; P.L., L.C. and H.H. write the manuscript, and all authors reviewed it. All authors have read and agreed to the published version of the manuscript.

Funding: This research was funded by the National Natural Science Foundation of China (Grant No. 11704426). This work was also supported by the Scientific Research Foundation of Guizhou Province Education Ministry (QJHKYZ[2019]055, QJHKYZ[2020]03, QJHKYZ[2017]252) and Outstanding Youth Science and Technological Innovation Talents Training of Zunyi City (ZYQK[2018]7). This work was also supported by Innovation and Entrepreneurship Training Program for College Students in Guizhou Province (202110664033, S202110664018, S202010664023).

Institutional Review Board Statement: Not applicable.

Informed Consent Statement: Not applicable.

Data Availability Statement: The data presented in this study are available on request from the corresponding author.

Conflicts of Interest: The funders had no role in the design of the study; in the collection, analyses, or interpretation of data; in the writing of the manuscript, or in the decision to publish the results. The authors declared that they have no conflict of interest to this work. 


\section{References}

1. $\quad$ Lu, B.S.; Zhang, Y.M.; Hu, T.Y.; Ma, Y.F.; Zhu, Y.N.; Liu, D.W.; Zhang, Z.Q.; Wang, E.H.; Ma, W.; Zhang, H.L. Non-fullerene acceptors based on multiple non-covalent interactions for low cost and air stable organic solar cells. Org. Electron. 2021, 93, 106132. [CrossRef]

2. Yu, J.S.; Xi, Y.Y.; Chueh, C.C.; Xu, J.; Zhong, H.L.; Lin, F.; Jo, S.B.; Pozzo, L.D.; Tang, W.H.; Jen, A.K.-Y. Boosting performance of inverted organic solar cells by using a planar coronene based electron-transporting layer. Nano Energy 2017, 39, 454-460. [CrossRef]

3. Duan, L.P.; Ashraf, U. Progress in stability of organic solar cells. Adv. Sci. 2020, 39, 1903259. [CrossRef]

4. Jeong, M.; Ho, C.J.; Lee, J.H.; Moon, D.K.; Kim, J.H. Effect of interface modification in polymer solar cells: An in-depth investigation of the structural variation of organic dye for interlayer material. Dyes Pigm. 2020, 173, 107927. [CrossRef]

5. Wang, C.H.; Yang, J.L. Interface modification for organic and perovskite solar cells. Sci. China Mater. 2016, 59, 743-756. [CrossRef]

6. Bi, S.Q.; Leng, X.Y.; Li, Y.X.; Zheng, Z.; Zhang, X.N.; Zhang, Y.; Zhou, H.Q. Interfacial modification in organic and perovskite solar cells. Adv. Mater. 2019, 31, 1805708. [CrossRef]

7. Arbab, E.A.A.; Mola, G.T. Metals decorated nanocomposite assisted charge transport in polymer solar cell. Mater. Sci. Semicon. Proc. 2019, 91, 1-8. [CrossRef]

8. Lin, Y.B.; Adilbekova, B.; Firdaus, Y.; Yengel, E.; Faber, H.; Sajjad, M.; Zheng, X.P.; Yarali, E.; Seitkhan, A.; Bakr, O.M.; et al. $17 \%$ efficient organic solar cells based on liquid exfoliated $\mathrm{WS}_{2}$ as a replacement for PEDOT:PSS. Adv. Mater. 2019, $31,1902965$. [CrossRef] [PubMed]

9. Duan, L.P.; Sang, B.R.; He, M.R.; Zhang, Y.; Hossain, M.A.; Rahaman, M.H.; Wei, Q.Y.; Zou, Y.P.; Uddin, A.; Hoex, B. Interface modification enabled by atomic layer deposited ultra-thin titanium oxide for high-efficiency and semitransparent organic solar cells. Sol. RRL 2020, 4, 2000497. [CrossRef]

10. Wang, D.F.; Tao, H.Z.; Zhao, X.J.; Zhang, T.J.; Han, J.B. TiO 2 /P3HT hybrid solar cell with efficient interface modification by organic and inorganic materials: A comparative study. J. Nanosci Nanotechnol. 2016, 16, 797-801. [CrossRef] [PubMed]

11. Khorshidi, E.; Rezaei, B.; Irannejad, N.; Adhami, S.; Ebrahimi, M.; Kermanpur, A.; Ensafi, A.A. The role of GQDs additive in TiO 2 nanorods as an electron transfer layer on performance improvement of the perovskite solar cells. Electrochim. Acta. 2020, 337, 135822. [CrossRef]

12. Huang, S.H.; Ali, N.; Huai, Z.X.; Ren, J.P.; Sun, Y.S.; Zhao, X.H.; Fu, G.S.; Kong, W.G.; Yang, S.P. A facile strategy for enhanced performance of inverted organic solar cells based on low-temperature solution-processed $\mathrm{SnO}_{2}$ electron transport layer. Org. Electron. 2020, 78, 105555. [CrossRef]

13. Liu, B.C.; Lan, L.H.; Liu, Y.Y.; Tao, H.; Li, H.M.; Xu, H.; Zou, J.H.; Xu, M.; Wang, L.; Peng, J.B.; et al. Improved performance of quantum dot light-emitting diodes by hybrid electron transport layer comprised of $\mathrm{ZnO}$ nanoparticles doped organic small molecule. Org. Electron. 2019, 74, 144-151. [CrossRef]

14. Peng, L.P.; Liu, Z.T. Reduce the hysteresis effect with the PEIE interface dipole effect in the organic-inorganic hybrid perovskite $\mathrm{CH}_{3} \mathrm{NH}_{3} \mathrm{PbI}_{3-\mathrm{X}} \mathrm{Cl}_{\mathrm{x}}$ solar cell. Org. Electron. 2018, 62, 630-636. [CrossRef]

15. Yu, H.Z.; Huang, X.X.; Huang, C.W. PEIE doped $\mathrm{ZnO}$ as a tunable cathode interlayer for efficient polymer solar cells. Appl. Surf. Sci. 2019, 470, 318-330. [CrossRef]

16. Kim, J.; Lee, H.; Lee, S.J.; Silva, W.J.; Yusoff, A.R.B.M.; Jang, J. Graphene oxide grafted polyethylenimine electron transport material for highly efficient organic devices. J. Mater. Chem. A 2015, 3, 22035-22042. [CrossRef]

17. Ling, Z.T.; Zhao, Y.; Wang, S.L.; Pan, S.H.; Lian, H.; Peng, C.Y.; Yang, X.Y.; Liao, Y.J.; Lan, W.X.; Wei, B.; et al. High-performance light-soaking-free polymer solar cells based on a lif modified ZnO electron extraction layer. J. Mater. Chem. C 2019, 7, $9354-9361$. [CrossRef]

18. Huang, Y.Y.; Li, S.N.; Wu, C.R.; Wang, S.; Wang, C.Y.; Ma, R.X. Introduction of Licl into $\mathrm{SnO}_{2}$ electron transport layer for efficient planar perovskite solar cells. Chem. Phys. Lett. 2020, 745, 137220. [CrossRef]

19. Sheng, Y.S.; Hu, Y.; Mei, A.Y.; Jiang, P.; Hou, X.M.; Duan, M.; Hong, L.; Guan, Y.J.; Rong, Y.G.; Xiong, Y.L.; et al. Enhanced electronic properties in $\mathrm{CH}_{3} \mathrm{NH}_{3} \mathrm{PbI}_{3}$ via $\mathrm{LiCl}$ mixing for hole-conductor-free printable perovskite solar cells. J. Mater. Chem. A 2016, 4, 16731-16736. [CrossRef]

20. Yin, S.M.; Yuan, Y.F.; Guo, S.Y.; Ren, Z.H.; Han, G.R. Li ${ }^{+}$Ion induced three-dimensional aggregation growth of single-crystal perovskite octahedrons. Cryst. Eng. Comm. 2016, 18, 7849-7854. [CrossRef]

21. Yin, S.M.; Tian, H.; Ren, Z.H.; Wei, X.; Chao, C.Y.; Pei, J.Y.; Li, X.; Xu, G.; Shen, G.; Han, G.R. Octahedral-shaped perovskite nanocrystals and their visible-light photocatalytic activity. Chem. Commun. 2014, 50, 6027-6030. [CrossRef]

22. Lee, H.W.; Oh, J.Y.; Lee, T.I.; Jang, W.S.; Yoo, Y.B.; Chae, S.S.; Park, J.H.; Myoung, J.M.; Song, K.M.; Baik, H.K. Highly efficient inverted polymer solar cells with reduced graphene-oxide-zinc-oxide nanocomposites buffer layer. Appl. Phys. Lett. 2013, 102, 193903. [CrossRef]

23. Li, P.; Jiang, Z.Z.; Huang, H.S.; Tian, S.J.; Hu, X.Y.; Li, W.J.; Bao, X.; Wang, Y. Improving electron transport by using a $\mathrm{NaCl} /$ Polyethylenimine ethoxylated double layer for high-efficiency polymer solar cells. Mat. Sci. Semicon. Proc. 2020, 116, 105150. [CrossRef]

24. Sirringhaus, H.; Brown, P.J.; Friend, R.H.; Nielsen, M.M.; Bechgaard, K.; Langeveld-Voss, B.M.W.; Spiering, A.J.H.; Janssen, R.A.J.; Meijer, E.W.; Herwig, P.; et al. Two-dimensional charge transport in self-organized, highmobility conjugated polymers. Nature 1999, 401, 685-688. [CrossRef] 
25. Uddin, M.A.; Lee, T.H.; Xu, S.H.; Park, S.Y.; Kim, T.; Song, S.; Nguyen, T.L.; Ko, S.J.; Hwang, S.; Kim, J.Y.; et al. Interplay of intramolecular noncovalent coulomb interactions for semicrystalline photovoltaic polymers. Chem. Mater. 2015, 27, 5997-6007. [CrossRef]

26. Cho, K.; Kim, J.; Yoon, S.Y.; Ryu, K.Y.; Jang, S.R.; Lim, B.; Kim, K. Reducing trap-assisted recombination in small organic molecule-based photovoltaics by the addition of a conjugated block copolymer. Macromol. Rapid Commun. 2017, 39, 1700630. [CrossRef] [PubMed]

27. Ghazy, O.A. Water-based blend nanoparticles of P3HT and PCBM for the application in organic solar cells. Adv. Polym. Technol. 2015, 34, 21500. [CrossRef]

28. Wang, Z.X.; Zhang, F.J.; Wang, J.; Xu, X.W.; Wang, J.; Liu, Y.; Xu, Z. Organic photovoltaic cells: Novel organic semiconducting materials and molecular arrangement engineering. Chin. Sci. Bull. 2012, 57, 4143-4152. [CrossRef]

29. You, D.S.; Kim, C.S.; Kang, Y.J.; Lim, K.; Jung, S.; Kim, D.G.; Kim, J.K.; Jo, S.J.; Kim, J.H.; Kang, J.W. Annealing-free poly(3-Hexylthiophene):[6,6]-Phenyl-C 61 -butyric acid methyl ester-based organic solar cells. Curr. Appl. Phys. 2012, 12, 908-910. [CrossRef] 